\title{
Argument appraisal strategy: A comprehensive approach ${ }^{1}$
}

\section{Robert H. EnNis}

University of Illinois, UrbanaChampaign

\begin{abstract}
A popular three-stage argument appraisal strategy calls for (1) identifying the parts of the argument, (2) classifying the argument as deductive, inductive, or some other type, and (3) appraising the argument using the standards appropriate for the type. This strategy fails for a number of reasons. I propose a comprehensive alternative approach that distinguishes between inductive, deductive, and other standards; calls for the successive application of standards combined with assumption-ascription, according to policies that depend for their selection on the goals of the appraiser; and provides for qualified reasoning.
\end{abstract}

Résumé: Une stratégie populaire pour évaluer des arguments consiste à (1) identifier les parties d'un argument, (2) déterminer si l'argument est déductif, inductif, ou un autre type d'argument, et (3) l'évaluer selon les critères appropriés. Cette stratégie échoue pour nombreaux raisons. Je propose une approche détaillee et complète qui distingue les differents types d'argument; emploie successivement l'application des critères et l'attribution des suppositions selon des méthodes reposant sur les buts de l'evaluateur; et s'addresse aux raisonnements nuancés.

Keywords: critical thinking, argument, argument appraisal, induction, deduction, qualified reasoning, value judging, assumptions, ceteris paribus, prima facie, probably

Typically, in critical thinking courses and textbooks, we try to teach students how to appraise different kinds of arguments that they encounter in their civic, vocational, and personal lives. A common strategy for doing so, endorsed by most critical thinking teachers to whom I have spoken, and evident in the structure of many texts (for example, the popular Copi \& Cohen (1998) has three sequential stages: identify, classify, and evaluate. In more detail, they are:

1) Figure out what the argument is (that is, identify the conclusion(s), reason(s), and perhaps also one or more assumptions);

2) Determine the type of the argument; that is, decide whether the argument is deductive, or inductive, or (for some texts) some other type, and

3 ) Evaluate the argument, applying the standards for the type decided upon in Stage 2: If the argument is deductive, apply deductive standards. If inductive, apply inductive standards. If some other type, apply the standards of that type.

Woods \& Walton have exhibited their support for this strategy by urging the 
importance of classifying an argument (second stage) before evaluating it (third stage):

We have stressed the need, in teaching informal logic, to include in the logical repertoire the skill of discerning the type of argument that the student is to evaluate. For if there is more than one type of argument, as we believe, the correctness or incorrectness of an argument may vary with the factor of type. For example, if there are inductively correct arguments, some of them (perhaps even all of them) may be deductively incorrect (invalid). Consequently, neglecting this type of distinction could spawn many a fallacy. For example, a systematic sophist might take one's correct inductive arguments and rule them deductively incorrect, ergo bad arguments. $(1979$, p. 5)

Samuel Fohr gives similar advice:

When faced with judging the worth of an argument philosophers will commonly decide how it is to be analyzed and only then examine it. In other words, antecedently to judging it they will decide how it is to be judged. If they decide it is an inductive argument they do not look to see if the premisses necessitate the conclusion. On the other hand, if they decide it is a deductive argument they do not examine whether or not the premisses render the conclusion probable. $(1980$, p. 6$)$

Trudy Govier suggests the same idea, but with a broader taxonomy of argument types:

To understand and evaluate an argument, we need a sense of what sort of argument it is: deductive, an inference-to-the-best-explanation, enumeratively inductive, analogical, or 'conductive' (a 'good reasons' argument) for instance. $(1999$, p. 85$)$

Although all this seems at first glance to be plausible advice, I shall in this essay argue that the strategy is unacceptable, and shall offer an alternative strategy that is more comprehensive and handles problems ignored by the three-stage strategy. As part of that program, I shall argue that the second part of the strategy, "discerning the type of argument" before evaluating it, which was urged by Woods \& Walton, Fohr, and Govier, is not feasible, partly because the distinction between deductive and inductive arguments is not viable. However, I shall suggest that there is a useful deductive-inductive distinction, though it is between sets of standards and not between types of arguments. ${ }^{2}$

I shall also suggest ways to deal with the fact that very few real arguments, as explicitly stated, actually satisfy deductive standards. ${ }^{3}$ There are actually two problems here. One is that people rarely state all premises in an argument that, when the putative gap is filled, would appear to be deductively valid. Commonly, this problem is resolved by adding the simplest more general proposition (a gap-filler) that makes the argument deductively valid, but unfortunately this gap filler, if, as is often the case, it is a universal generalization, is often false, automatically making the argument defective. The other problem, often ignored, is that though many arguments appear to come close to satisfying deductive standards (usually after 
reasonable assumptions are added), they include implicit or explicit qualifying terms like 'generally', 'probably', 'ceteris paribus', and 'prima facie', which usually render them deductively invalid.

The first stage of the three-stage strategy is also problematic. Just what constitutes the argument? One possibility is that the argument is exactly the conclusion and reason(s) stated by the author, and nothing more. A second possibility is the commonly implemented policy of adding the simplest proposition that turns the argument into a deductively valid argument.

Another possibility is that the argument is what the author said, plus unstated assumptions that the author believed and used in formulating the argument (Johnson, 1996, p. 68). A fourth possibility is that the argument consists of what the author said or used (where cogent) plus the assumptions that are needed to make the argument be at its best, all things considered (for example, Thomas, 1986).

A final possibility is that the choice among the above four alternatives should depend on the appraiser's purpose, which justifiably varies with the context. Along with David Hitchcock (1996, pp. 274-275), I am in this last camp, and will presently consider these alternatives more fully. Critical thinking textbooks are not in agreement and are rarely helpful about how to go about ascribing assumptions to an argument, a problem that extends beyond the promotion of the three-stage strategy.

In this paper, I try to provide an integrated comprehensive reasonable resolution of these interdependent problems. Although I do not here argue for, nor take a stand about, the number or nature of types of argument standards, I shall use the taxonomy I favor to exemplify the overall argument appraisal strategy for which I do argue. For the basic purposes of this essay, an alternative taxonomy, such as Trudy Govier's "pluralist view" (1999, p. 108), or Brian Skyrms's (1975) "positivist view" (Govier's language), would do as well, so long as it is in the form of sets of standards. Govier (1999, pp. 107-122) has helpfully depicted and discussed most of the would-be argument taxonomies operating in the fields of informal logic and critical thinking these days.

Let us start by trying to apply the three-stage strategy to the argument in Example 1. It was offered by a pathologist in a murder trial in which I was a juror.

\section{Example 1:}

The knife blow was of moderate force [as opposed to strong force] because the knife penetrated only $21 / 2$ inches and there were no knife marks on the bones of the victim.

The knife blow, I should note, penetrated the victim's heart and killed him.

Our job as jurors in this trial, among other things, required us to decide whether to accept the conclusion that the knife blow was of moderate force. The judge told 
us that we were to determine the facts of the case, based on testimony and exhibits presented in the courtroom-and a visit to the house in which the killing took place. The moderate-force conclusion was a factual statement in that situation, one about which we needed to decide.

The situation had in the background a severe standard of proof, proof beyond a reasonable doubt, although this standard did not need to be applied to the pathologist's moderate-force conclusion. That conclusion instead was relevant in the context because it justified doubt about a complicated condition (stipulated by the judge) to which the proof-beyond-a-reasonable-doubt-standard applied and that was a necessary condition for a murder verdict. The crucial part of this complicated condition, to simplify, was that the defendant knew that her act created a strong probability of great bodily harm to the victim. Primarily because we accepted the pathologist's conclusion, we judged that this crucial part of the complicated condition had not been proved beyond a reasonable doubt-and therefore that the defendant was not guilty of murder.

Admittedly, the situation was unusual in that we jurors were not able to ask questions, and were not able to pursue investigations outside of the jury room. But we did have a wealth of information about the situation that was not included in the pathologist's testimony.

According to my application of the first (the identification stage) of the threestage strategy to Example 1, the conclusion is "The blow was of moderate force", and the explicitly stated reasons are "the knife penetrated only $21 / 2$ inches" and "there were no knife marks on the bones of the victim". For the time being, I will only consider the explicit argument, and will later look at the effect of adding assumptions.

At the second stage of the three-stage strategy, assuming for the time being that the argument is either deductive or inductive, we must decide which it is. Following the three-stage strategy, we must resolve that question before we apply evaluative criteria, so that we will know which criteria to apply.

\section{Section I. Is it deductive or inductive?}

It would be easy if the argument came labeled "deductive" or "inductive", as might implicitly happen in a textbook. Unfortunately, life is not like that, but this is only a part of the problem for our students. More important is the fact that the nature of the putative distinction between deductive and inductive arguments is itself not agreed upon. There were those highly respected philosophers who treated inductive arguments as those that lead from particulars to a generalization, and deductive arguments as those that lead from a generalization to particulars (for example, Creighton, 1922, p. 384; Mill, 1872, pp. 133-134; and Whewell, 1858, pp. 43, 48). Although many of our students come to our critical thinking courses with this version of the distinction in mind, most contemporary teachers of, and textbooks 
in, critical thinking and informal logic reject it, and use one or the other of two basic approaches (soon to be elaborated) related to strength of support. Realize, however, that some contemporary textbook authors, for various reasons, are not happy with the distinction, including Govier (1980, 1987), Johnson \& Blair (1983), Michael Scriven (personal communication), and Weddle $(1979,1980,1987)$.

The fact that there are different popular basic accounts of the distinction does not necessarily mean that the classification stage of the three-stage process will not work, but it tends to make application confusing, and warns us that there might be problems with each of the approaches. I shall argue that indeed there are serious problems with each approach that I have found, effectively disabling the three-stage approach. Let us look first at the basic two that involve strength of support because they are most popular with contemporary critical thinking teachers and authors.

\section{The standard putative distinctions that involve strength of support}

Two different strength-of-support accounts are found in contemporary critical thinking and informal logic textbooks (noted by Perry Weddle, 1987). I shall call them the "psychological" and "achievement" accounts. The psychological account distinguishes on the basis of what is attempted, claimed, intended, purported, believed, etc., to be achieved by the argument. The achievement account distinguishes on the basis of what the argument actually achieves.

\section{The psychological account}

Here are some examples exhibiting the psychological account, starting with one by Nicholas Rescher:

An argument that attempts (or is claimed) to provide conclusive evidence for its conclusion is called a deductive argument. In contrast, an inductive argument attempts (or is claimed) simply to provide some grounds for the conclusion-that is, to furnish good reasons for accepting the conclusion without providing conclusive evidence for it. (1964, p. 60, italics added).

Irving Copi puts it this way:

A deductive argument is one whose premises are claimed to provide conclusive evidence for the truth of a conclusion. [Inductive arguments claim] to establish them as probable or probably true. (1962 (but unchanged in 1998), p. 133, 337, italics added)

Moore \& Parker state the distinction similarly, though they add the word "absolutely" to the conclusiveness, and speak of intentions, rather than attempts and claims:

Deductive arguments are those whose premises are intended to provide absolutely conclusive reasons for accepting the conclusion; inductive arguments are those whose premises are intended to provide some support, but less than conclusive support". (1995, p. 189, italics added) 
Moore \& Parker do not say anything about the range between "absolutely conclusive" and "some..., but less than conclusive".

So far, we have examples of the use of the terms, 'attempt', 'claim', and 'intend' in drawing the psychological distinction in critical thinking and informal logic textbooks. Without the full quotations, I also note the use in drawing this distinction of 'purports' and 'believes', as in "purports to be a good reason..." (Black, 1967, p. 169), and "believes that the truth of the premises necessitates..." (Vorobej, 1992). Black's and Vorobej's accounts appear not in textbooks, but in scholarly articles.

Because arguments are not living purposeful creatures, they do not literally attempt, claim, intend, purport, or believe. Rather it is people, usually argument authors, who do those things with arguments (noted by Weddle, 1979, p.2), although a non-author could put an author's argument forward with endorsement.

Sometimes an argument is just being considered without any proponent. Then it would not be classifiable at all by those advocating a psychological approach, since no one is making a claim, etc., about it, constituting a problem for the psychological approach. Bypassing this sort of case, and barring evidence to the contrary in a particular case, I shall assume, that the attempters, claimers, intenders, purporters, believers, etc., are the authors of arguments, unless otherwise indicated. The forthcoming discussion also applies to non-author endorsers-with appropriate modifications.

There are differences among attempting, claiming, intending, purporting, and believing. For example, someone could (deceptively) claim the evidence to be conclusive without intending it to be so, or attempting to make it so, or believing it to be so. But for purposes of this essay, the differences do not matter, so I group them together under the label, "psychological", along with 'trying', 'supposed to' (a term I use in my text), "meant to', and other words referring to or implying the arguer's mental states and actions. What I say about one fits each other-with appropriate modifications.

\section{The achievement account}

In using the achievement account of the distinction, we look at what the argument actually achieves. Here is Wesley Salmon's depiction:

DEDUCTIVE: If all of the premises are true the conclusion must be true; all of the information ... in the conclusion was already contained ... in the premises. INDUCTIVE: If all the premises are true, the conclusion is probably true.... The conclusion contains information not present in the premises. (1963, p. 14)

According to Wesley Salmon then, an argument that achieves deductive validity is a deductive argument; and an argument that achieves the implication by the 
premises of the probable truth of the conclusion is an inductive argument.

Others subscribing to some version of the achievement account include Walton (1989), Cederblom \& Paulsen (1986), and Kahane (1980).

\section{A basic problem with the psychological account}

The pathologist who offered the argument in Example 1, if she had said what she was intending, attempting, or claiming to do, would, I believe (on the basis of her demeanor), have claimed that she was providing conclusive evidence. So the argument would be a deductive argument, using the psychological accounts in textbooks by Rescher and Copi. I also believe that the pathologist intended to provide "absolutely conclusive reasons" (if the choices are, as they seem to be, only "absolutely conclusive reasons" and "some support, but less than conclusive support" in the Moore \& Parker scheme), making hers a deductive argument on the Moore \& Parker psychological account. Supporting this interpretation is the fact that Moore \& Parker did not consider the range between "absolutely conclusive reasons" and "some support, but less than conclusive support". They say that "absolutely conclusive" implies deduction, and "less than conclusive"- - with "some support" implies induction. The pathologist's demeanor suggested that she thought her premises provided considerably more than "some support, but less than conclusive, support".

If Example 1 is thus to be deemed a deductive argument, and if, as I believe and for the time being shall assume, it is a very good argument because it well satisfies inductive (best-explanation) standards (to be summarized later), given the other information provided in the trial; then it must paradoxically be judged to be an unsatisfactory argument by these psychological accounts. Applying deductive standards, as required by its being classified a deductive argument, it is deductively invalid. Accordingly, it must be judged unsatisfactory-even though it is a good argument-thus exhibiting a serious problem with the psychological approach.

If someone objects to assuming Example 1 to be a very good argument (after reading the extended discussion of it in Section IV), then I invite the person to substitute an example of an argument that in the person's view satisfies bestexplanation standards (but not deductive standards) well enough for the person to be willing to say that the evidence is conclusive. ${ }^{5}$ Then there is a problem because the conclusion does not follow necessarily in the deductive logic sense of 'follows necessarily', even though the person who puts it forward claims the evidence to be conclusive.

For the sake of simplicity, I shall limit the rest of this discussion to the Copi account. The same general points can be adapted to other psychological accounts when they are used in the attempt to identify deductive arguments. 


\section{An objection to this challenge to the psychological account}

Someone might say, "But if asked whether her argument provided conclusive evidence for her conclusion, the pathologist, in answering affirmatively, would not have meant by 'conclusive' what Copi meant by the word. For Copi, the proposition, 'An argument provides conclusive evidence for its conclusion' means the same as 'The conclusion necessarily follows from the evidence, that is, the argument is deductively valid.' (And if he did not mean something that strong, then what right do we have to apply deductive standards to what he calls deductive arguments?)" However, this possible reply, although probably true, misses the point, as I shall now argue:

In my years of experience teaching deductive logic, I have found that most people I know who are not previously schooled in deductive logic do not have the deductive concept of necessarily following. Copi's distinction, as I urged earlier, must be based on the claim of the arguer (or the person putting the argument forward, in which case the same reasoning applies to that person), if it is to make any sense. The arguer cannot claim what is not in her conceptual scheme. If the pathologist is like most people, there is no basis for attributing to her a claim that the conclusion necessarily follows (in the deductive logic sense). So the pathologist's presumed claim that the evidence is conclusive must be taken in a sense in which she could have meant it -not as the deductive 'necessarily following', but rather as proof that is very strong. So she would have claimed that her evidence was conclusive, making hers a deductive argument, under the psychological view. It is her argument, and she was attempting to provide conclusive evidence. The test, using the psychological account, must lie in the author's intentions, claims, attempts, purports, or beliefs. Application of the test results in judging a good argument to be defective.

\section{Beardsley's disjuncts}

Monroe Beardsley interestingly, appeared to want it both ways. He offered a disjunction incorporating both the achievement and psychological accounts:

A deductive argument is an argument that either is or claims to be valid. All other arguments are inductive. (1975, p. 23, italics added)

My objection to the psychological account of the inductive-deductive distinction extends to Beardsley's second disjunct ("claims to be valid"). It would have to classify the knife blow argument as deductive, since most people do not mean by 'valid' what 'valid' means in deductive logic. Rather, by 'valid', they roughly mean "well grounded". The American Heritage Dictionary of the English Language (2000, p. 1899) gives "well grounded; just" as its first meaning. The Random House Dictionary of the English Language (Urdang \& Flexner, 1968, p. 1453) gives "sound; just; well-founded" as its first meaning. My old Webster's Collegiate Dictionary (Fifth Edition, 1947, p. 1105) gives "founded on truth or 
fact; capable of being justified, supported, or defended; well-grounded; sound" as its primary meaning. Accordingly, I shall henceforth use 'valid' to mean "wellgrounded", except when modified by 'deductively' or 'deductive', as in "deductively valid" and "deductive validity".

Beardsley's achievement disjunct ("is valid") classifies Example 1 as inductive, if it is Beardsley, or his logically knowledgeable surrogate, making the judgment of validity (assuming that Beardsley, like most philosophers, uses the word 'valid' to mean "deductively valid") because the argument is not deductively valid. But this disjunct would then, because it would then be an achievement account, have the problems I shall presently elucidate in discussing the achievement account.

If, on the other hand, the classification judgment using the disjunct, 'is valid', is made by someone not knowledgeable in logic, then that person would probably interpret the disjunct to mean "is well grounded" and would be required by Beardsley's definition to judge as deductive all arguments that are inductively valid but not deductively valid. As with the psychological disjunct, then, good arguments would be judged defective because they do not satisfy deductive standards. Later I shall discuss Beardsley's disjunction as a whole.

\section{Even if most people do grasp the concept of deductive validity...}

I realize that, up to this point, the argument against the psychological account is primarily based on the claim that most people unschooled in deductive logic do not use 'conclusive evidence' and 'valid' to imply that the conclusion necessarily follows in the deductive logic sense of 'necessarily follows'. If this claim is wrong, then the psychological approach avoids the problem set forth, except for those people who do not have the concept of deductive validity-and there clearly are at least some of them. But the approach still does not help us decide which kind of argument the pathologist attempted to offer. It did not come with a label on it. She did not indicate that she was claiming to offer a very strong proof, rather than a deductively valid one. Without such an indication (even assuming that she might have the distinction), we are on the face of it unable to classify her argument at Stage 2 of the three-stage, classification-before-evaluation strategy. So the strategy still fails us in dealing with the moderate-force example. Vorobej (1992) offers a tempting way out of this difficulty, but, as I shall argue, it does not succeed.

\section{Mark Vorobej's belief account}

Vorobej has provided an interesting and lively defense of his psychological account of deductive argument, a belief account that he calls "(D)":

(D) An argument is deductive if, and only if, the author of the argument believes that the truth of the premises necessitates (guarantees) the truth of the conclusion. In other words, in a deductive argument the author of the argument believes that it is not logically possible for all the premises to be true and the conclusion to be false. (1992, p. 105) 
Of particular note are (1) the use of the word 'believes', making his a psychological account; and (2) the explicit requirement that the belief be about the satisfaction of Vorobej's concept of logical necessity, rather than conclusiveness of the evidence (as construed by the arguer). He notes some advantages of his definition over some other attempts to define 'deductive argument', and defends his definition against objections, including two objections that are similar to those I raise against other psychological accounts. In the context of using the three-stage strategy, which he appears to endorse (pp. 106, 107), I shall summarize my objections to the other psychological approach, and consider his responses. There are many other interesting and valuable aspects of his article that I must neglect in order to focus on the theses that I am developing in this essay.

Incidentally, because logicians have advanced a number of technically different concepts of logical necessity and Vorobej has given us only one, I shall refer to it as "Vorobej's concept of logical necessity". But the same general points hold for all the ones with which I am familiar.

The First Objection. One objection I urge against earlier-quoted psychological accounts is that most people do not possess any logician's concept of logical necessity, of which Vorobej's is an example. So definitions of 'deductive argument' in terms of intended conclusiveness result in judging good arguments (that are not deductively valid, though intended by their authors to be conclusive) to be deductive, and therefore bad arguments because they are not deductively valid. Vorobej's definition of 'deductive argument' avoids this specific objection by not using the idea of intended conclusiveness, but rather using the idea of a believed necessity that is clearly logical necessity in view of his clarification, "not logically possible for all of the premises to be true and the conclusion to be false". But he does not thereby avoid a basic problem-that most people do not have Vorobej's, or any logician's concept of logical necessity, and so can not have a belief that an argument exhibits logical necessity —even about their own deductively valid arguments. The best they can believe, using their concepts, are things like "Such an argument conclusively establishes the conclusion", or "The conclusion follows beyond a reasonable doubt". They could even say, "The conclusion follows necessarily" - without meaning what a logician means by 'follows necessarily'. So by Vorobej's criterion, which is claimed to be both necessary and sufficient, at the second stage of the three-stage strategy, almost all arguments (in this world, where almost all people are not trained in deductive logic) are classified as non-deductive because almost all arguments, even deductively valid ones, do not satisfy his criterion.

So, at the second stage of the three-stage classify-before-evaluate approach, Vorobej's definition would fail to send us to the deduction section of the textbook to see how to judge those deductively-valid arguments that are actually put forward by ordinary people. It fails to do this because most people do not believe about their own deductively valid arguments that it is not logically possible for all 
of the premises to be true and the conclusion to be false. They do not even understand what that means. They do not have Vorobej's concept of logical necessity.

One Reply to the First Objection. Vorobej, in reply to this sort of objection, expresses his "serious reservations about the claim that few 'ordinary' reasoners will be able to, or will only very infrequently present, deductive arguments" ( $p$. 114). By "present, deductive arguments", I remind you that he means, "present arguments such that they [the arguers] believe that it is not logically possible for all the premises to be true and the conclusion false." So he has reservations about the claim that few people can do that, that is, can have beliefs about the applicability of Vorobej's concept of logical necessity. I find these reservations surprising, in view of my experience teaching logic and critical thinking and the experiences of people with whom I have informally spoken about the matter. Govier $(1980$, p. $7 ; 1987$, pp. 42, 46) has in print expressed our view.

Vorobej suggests that this is "really a sociological issue that ... [he] cannot properly explore here" (p. 114). Actually, it is a difficult issue that is hard to explore well in an empirical sociological study. However, one step he might take is to look closely at his or his colleagues' experiences in teaching deductive logic in a critical thinking course to most undergraduates (not math, engineering, and computer-science majors, most of whom, in my experience, do have a concept of logical necessity), but no relevant study has been done, to my knowledge. ${ }^{6}$

To buttress this reservation, Vorobej offers an analogical argument:

The argument that people who do not understand the phrase 'logical necessitation' cannot present deductive arguments bears an uncomfortable resemblance to the claim that people who do not understand the words 'androcentric' or 'misogynist' cannot exhibit gender biased behavior or utter sexist remarks. (pp. 114-115)

Remembering his definition of 'deductive argument', we see that the proposition he analogizes is that people who do not understand the phrase 'logical necessitation' cannot present arguments such that they [the arguers] believe that "it is not logically possible for all the premises to be true and the conclusion false." Actually, this proposition seems true, but it is not analogous to the "androcentric/ misogynist" alleged analogue. What would be analogous to this alleged analogue would be the proposition that people who do not understand the phrase 'logical necessitation' cannot present deductively valid arguments. This proposition is obviously false-like the analogue. Most people can and do present deductively valid arguments, even if in ignorance of Vorobej's concept of logical necessity. The proposition that is refuted by the analogy is not one that I have claimed, nor that I have ever heard asserted.

A Second Reply to the First Objection. Vorobej is aware that his definition could send us to the wrong place in the critical thinking book, but thinks that it is only a problem of the psychological costs of flexibility and "relinquishing cherished intuitions": 
Any classically recognized deductive argument (modus ponens, hypothetical syllogism, etc.) could be non-deductive...according to (D) if the beliefs of the argument's author are sufficiently eccentric or confused....That (D) deviates from some current practice of classifying arguments is no argument against (D) (except in the obvious utilitarian sense that there may be psychological costs associated with relinquishing cherished familiar intuitions while acquiring new ones. (pp. 107, 108)

Suppose that some "sufficiently eccentric or confused" person (any one of the vast majority of people in the world who do not possess Vorobej's concept of logical necessity) has offered a deductively-valid hypothetical syllogism. This person is not able to believe "that it is not logically possible for all the premises to be true and the conclusion to be false", because the person does not have the concept. So Vorobej classifies this person's deductively-valid argument as non-deductive. Under the three-stage approach, where would Vorobej send the person to read about hypothetical syllogisms and other arguments containing a series of hypotheticals? Presumably, he would send the person to the section of the critical thinking book dealing with deductive logic, or to a deductive logic book. But how could Vorobej justify that if he thinks the argument is non-deductive? The "cherished intuition" is deeply embedded.

Rightly so. We need a field that deals with the application of the logician's concept of logical necessity. Given that such a field exists (whatever its name), that is the place to send people for advice about deductively-valid hypothetical syllogisms because hypothetical syllogisms are usually expected to satisfy the demands of the concept of logical necessity, and get their strength from so doing. That field is the place to send such people, even if they do not believe about their deductively-valid hypothetical syllogisms that they satisfy the concept of logical necessity. But Vorobej would not send them there because their belief system is eccentric or confused, though prevalent. Where would they go?

Second Objection. My second objection is that, even if the concept of logical necessity were widely distributed, the psychological account (and in Vorobej's case, the belief version of that account) would not help us to classify the moderate force example, because, even assuming that the pathologist in the moderate-force example has Vorobej's concept of logical necessity, we do not know whether the pathologist believes her conclusion to be logically necessitated by the premises, or believes it to be conclusively established by an argument satisfying inference-tobest-explanation standards. She did not tell us which she believed, as is usually the case in the real world. So Vorobej's belief definition would not help someone trying to use the three-stage approach to classify most arguments before evaluating them.

Vorobej's Response to the Second Objection. To this objection, Vorobej's response is that, assuming that the arguer is a reasonable person, "one can ask oneself what a reasonable person would believe about the strength of the logical link within the argument, and conclude, if there is no evidence to the contrary, that the author of the argument shares this belief" (p. 111). This reply harbors an 
ambiguity. Does the reasonable person have the concept of logical necessity or not?

If so, then Vorobej's position becomes a strong version of the achievement account, under which an argument is deductive just in case it is deductively valid. That is, if the argument is deductively valid, then it would be classified as deductive. If the argument is not deductively valid, it would be classified as non-deductive. A problem I shall elaborate later is that it would then classify standard deductively invalid arguments, such as affirming-the-consequent, denying-the-antecedent, and undistributed-middle arguments, as non-deductive, and would fail to send students to the deductive section of the book (or to a deductive logic book) to learn how to evaluate them.

If, on the other hand, the reasonable person does not have Vorobej's concept of logical necessity, then Vorobej's account is back in the same trouble: All arguments, even those that are deductively valid, would be classified as nondeductive because this reasonable person, not having Vorobej's concept of logical necessity, would not believe of any argument (including deductively valid ones) that "it is not logically possible for all the premises to be true and the conclusion to be false." In attempting to follow the three-stage approach, we would be sent to the wrong place to find standards to judge the deductively-valid arguments propounded or examined by this reasonable (but not-logically-sophisticated) person.

In the context of the three-stage strategy of argument appraisal, there is another problem with the "reasonable person" response. It requires evaluation by the argument appraiser prior to classification, making classification an unnecessary step in argument appraisal. Bypassing classification, as you shall see, is also a strategy I recommend, but it is inconsistent with the three-stage classify-first strategy.

Summary of the Vorobej Discussion. I have urged that the concept of logical necessity is not widely distributed, making Vorobej's belief-in-logical-necessity criterion unusable for the arguments of most arguers, and that his analogical argument misses the mark. Furthermore, his reasonable-person reply is ambiguous. Either it transforms his account into a strong achievement account (to be discussed shortly), or it leaves the account with its basic problem: Application of the account results in many deductively-valid arguments being judged non-deductive, resulting in our being sent to the wrong place. In addition, in the context of the three-stage argument-appraisal strategy, the reasonable-person approach requires evaluation before classification, in violation of the required ordering of the threestage strategy. In sum, Vorobej's definition and comments do not rescue the threestage strategy of argument appraisal, and at best work only for logically-sophisticated arguers. 


\section{Evaluating the achievement account}

Using Wesley Salmon's and other achievement accounts, the moderate-force argument of Example 1 would not be deductive, because not all the information in the conclusion was contained in the premises. Also, it is not the case that "if all the premises are true, the conclusion must be true" in the sense Salmon intended. Given Salmon's account of inductive arguments, then, his account probably sends us to the right part of the critical thinking book to find standards for evaluating Example 1.

However, a problem peculiar to the achievement account is that it fails to classify as deductive those arguments that are generally deemed deductively invalid, and that are studied in the deductive section of the book, including Example 2:

\section{Example 2:}

All the racists in town are at the meeting featuring a speaker condemning affirmative action.

Frank is at this meeting.

Therefore, Frank is a racist.

In Example 2, it is not the case that "if all the premises are true the conclusion must be true; nor is it the case that "all of the information ... in the conclusion was already contained ... in the premises" (as specified in Salmon's achievement account). By the achievement account, then, Example 2 is not deductive, yet the deductive part of most critical thinking books ${ }^{7}$ is the place where we find advice about how to judge this argument. Furthermore, by achievement accounts, it is not inductive either because in the situation in which it was offered, the truth of the reasons did not make the conclusion probably true. Salmon does say that there are logically correct and incorrect types of both deductive and inductive arguments, but that still leaves us in the dark about how to identify, and where to look for advice about, the "logically incorrect" types, given that we are adhering to the classification-before-evaluation feature of the three-stage view.

A second problem for the achievement account under the three-stage view is that it violates the view's sequential ordering. The achievement account requires appraisal of the argument prior to classification. For example, we must know an argument to be deductively valid in order to decide that it is deductive. But the three-stage view calls for classification prior to appraisal.

\section{Two other possible accounts}

Are there any other accounts of the distinction between deductive and inductive arguments that are viable? The fact that almost all textbook authors choose either the psychological or achievement account is reason to be pessimistic. But let us 
consider two others that I have mentioned: Beardsley's disjunction account that combines the psychological and achievement accounts in a disjunction, and the generalization account that we often find our students bringing to our classes.

\section{Beardsley's disjunction account}

Both alternatives of Beardsley's account on their own, I have argued, are defective, but is the disjunction ("is valid or claims to be valid") viable? I think not. Assuming that Beardsley means 'deductively valid" when he says "is valid", let us apply his disjunction to the pathologist's moderate-force argument of Example 1. Since Example 1 is not deductively valid as it stands, the first alternative, "is valid", does not hold. But the second alternative, "claims to be valid" would hold, assuming that the pathologist was not familiar with the concept of deductive validity, and would have been using, if asked, the definition of 'valid' I offered earlier from my primary dictionary, "well grounded". Note that I am interpreting the word "valid" in Beardsley's sense in the first disjunct, and in the pathologist's sense (assuming that hers is in accord with the dictionary's sense) in the second disjunct, because Beardsley and the pathologist respectively would be making the alternative claims depicted in the disjunction, "is valid or claims to be valid". Because the satisfaction of either disjunct implies the satisfaction of the disjunction, Beardsley's account would classify the pathologist's moderate-force argument as deductive, requiring us to judge a good argument as defective (using deductive standards).

\section{The generalization account}

The generalization account is that deductive arguments go from generalizations to particulars, and inductive arguments go from particulars to generalizations. This account would not produce a decision for the explicit version of Example 1, the moderate force example, because there is no generalization in it. More specifically, even though it is an inductively-valid argument, ${ }^{8}$ its conclusion is not a generalization, so it would not be classified as inductive.

Example 2, the racist example, fares better under this account because this example provides reasoning from a generalization to a particular. So we are sent by it to the deductive part of the critical thinking text, which is where one will find advice for dealing with this argument.

However, for many arguments discussed in the deductive section of the book, the generalization account would fail to send us to that section because the premises contain no generalization. Standard basic arguments that fit the form of the propositional calculus are examples, as in Example 3:

\section{Example 3:}

If Mary hit a home run at her first time at bat yesterday, her sister congratulated her. 
Her sister did not congratulate Mary.

So Mary did not hit a home run at her first time at bat yesterday.

Example 3 is a standard deductively valid argument of the form, denying the consequent (or, as some like to say, modus tollens). Yet there is no generalization in the premises. So the generalization account is unsatisfactory here as well. ${ }^{9}$

In sum, the generalization account fails for inductively valid arguments that do not have a generalization for a conclusion. It also fails for deductively valid arguments that do not have a generalization in the premises. Part of the problem is simply that current textbooks are not written with the generalization approach in mind. But the basic problem is that the generalization approach does not send us anywhere for advice about arguments that do not contain generalizations.

I can think of no account of a distinction between deductive and inductive arguments that does not suffer from one or more of the problems depicted. What is a student then to do at the classification stage, if, as I have argued, the distinction is not viable? Would adding assumptions help? Unfortunately, the problems remain, even if we pursue any of a variety of assumption-ascription approaches, as I shall now argue.

\section{Section II. Ascribing implicit assumptions}

The first of the three-stages of the classification-before-evaluation strategy is to identify the parts of the argument. At this stage, it is not agreed among textbooks and other authorities whether the identified parts of the argument should include its unstated assumptions, if any, and if so, how to tell what assumptions should be ascribed to an argument. So far in this essay, I have been looking only at the explicit argument (in effect employing a no-added-assumptions policy) and concluded that existing attempts to distinguish between deductive and inductive arguments are not viable, and that, in part because of this, the three-stage strategy does not work. But it is often urged that we consider the implicit assumptions in an argument, making them part of the argument as well. I shall next consider four other policies for ascribing assumptions: simple deductive-assumption ascription, used-assumption ascription, needed-assumption ascription, and goal-oriented assumption ascription. I shall explain each and argue that under each, the deductive/ inductive argument distinction is not viable and the three-stage strategy does not work. If, as I believe, there are no other plausible assumption ascription policies, the prospects for a useful distinction between deductive and inductive arguments look dim, especially at the classification stage of the three-stage process.

\section{Simple deductive assumption ascription}

Let us next explore the consequences of the common policy of adding what appears to be the simplest proposition that makes the argument deductively valid, but 
that also is more general than the claim that the reasons imply the conclusion, and that, in making the argument deductively valid, uses all the explicit reasons. A convenient name for such assumptions is 'simple deductive assumptions'. An example: to the moderate-force argument we might add the proposition, 'Knife blows that penetrate $21 / 2$ inches and do not produce any marks on the bones of a victim are of moderate force.' If this proposition were added to the argument, we would have a deductively-valid argument (because we deliberately chose a proposition that would make it deductively valid).

Unfortunately, in this case the policy yields a proposition that is false, refuted by some obvious counterexamples: Victims sometimes can raise their arms, and deflect a blow; or the victim might have been wearing a thick leather jacket, resulting in diminishing the force of the blow. Hence ascribing that proposition as an assumption in this case would require that the argument be judged defective, even though it is deductively valid-defective because it has a false reason. In the technical sense of the term, 'sound', it is not sound.

(Henceforth, I shall use the word 'sound' in this technical sense: 'deductively valid with true (or acceptable) reasons'. So a sound argument necessarily has a true (or acceptable) conclusion. I shall just assume for the purposes of this essay that the word 'acceptable' can fit into that definition. If this makes you uncomfortable, ignore it. The basic theses of this essay are not thereby affected. I am thus pursuing my resolution not to become involved here in controversies about particular details of standards and taxonomies of standards, leaving those difficult topics to another day-even though for purposes of illustrating the basic theses, I assume a set of standards and a taxonomy that I favor.)

Under this policy, the standard psychological approach would fail because it would classify the pathologist's good moderate-force argument as deductive for the same reason as before, and consequently defective. The Vorobej version of the psychological approach would work for the pathologist's moderate-force argument (even though it would, as I noted earlier, oddly classify a deductively valid argument as non-deductive), but it still is inadequate because it does not allow arguments of people who do not have the concept of deductive validity to be deductive even when their arguments satisfy standards of soundness (and thus satisfy deductive standards).

The achievement approach would classify the argument as deductive because it now is deductively valid. But this good argument would then be judged defective because it is now unsound (having a false premise), showing that the achievement approach also fails. Under both disjuncts of Beardsley's conception, the argument would be deductive, showing, as with the straight psychological and achievement approaches, that it is not satisfactory. Lastly, the generalization approach would classify the argument as deductive because there is a generalization in the premises now, but the argument would then be judged defective because of its false premise. So the generalization approach also fails because it too implies that a good argument is defective. 
I realize, however, that considering the addition of the simplest implicit proposition that converts an argument into a deductively-valid argument often does seem to be at least a reasonable exploratory move in argument appraisal. This is partly because without supplementation very few good arguments in everyday life (personal, vocational, political, intellectual) actually provide by themselves sufficient reason to draw the conclusion, and partly because drawing attention to that specific supplementing proposition often reveals a flaw in the argument. Consider Example 4, which I offered in a situation in which there was a severe drought. I was pessimistic, but hoping for rain:

\section{Example 4:}

There is no thunderstorm nearby because we have heard no thunder recently.

In that situation, the conclusion was, "There is no thunderstorm nearby." I did not bother explicitly to add a simple proposition that would make the argument deductively valid, "Whenever there is a thunderstorm nearby, we will have heard thunder in the recent past." My explicitly adding this proposition in conversation would generally be unnecessary, and avoided in most situations-in line with Grice's conversational maxims, two of which are, "Do not make your contribution more informative than required" and "Be brief" (1990, p. 152).

In the situation in which the thunderstorm example was offered, it seemed appropriate for an argument appraiser to add the stated proposition that makes the argument deductively valid, to accept that proposition provisionally, and to judge that the conclusion, "There is no thunderstorm nearby", is therefore acceptable, even though, as in the moderate-force case, the original explicit argument is deductively invalid. However, in other situations, the thunderstorm argument might not be a good one-if, for example, I were inside the house, playing loud music, or if I were deaf. ${ }^{10}$ In such a case, ascribing that same assumption could be useful as a way of exhibiting a probable defect in the argument, a defect that shows that we probably should not draw the given conclusion.

All four of the approaches to a distinction between deductive and inductive arguments appear to succeed with this supplemented thunderstorm argument. All classify it as deductive; it appears to be deductively valid; and it seems to satisfy soundness standards in the situation in which it was offered. I have just used the word "appear(s)" (twice) because of some reservations I shall later express in the section entitled "Qualified Reasoning".

Thus, as illustrated by the moderate-force example, the three-stage strategy can result in mistaken evaluations for a simple deductive-validity-producing assumption, whatever the approach to the definition of 'deductive argument'. However, as illustrated by the thunderstorm example, adding a simple deductive-validity-producing assumption, it appears, does not always produce mistaken evaluations. 


\section{Appraising the arguer or the arguer's presentation: Ascribing used assumptions}

So far, I have considered two assumption-ascription policies: adding no assumptions, and adding simple deductive assumptions. Under each policy, the threestage process did not work and the various approaches to distinguishing between deductive and inductive arguments were not viable. Would more flexibility in ascribing assumptions help, using policies outlined at the beginning of this essay? No, I shall argue.

A third assumption-ascription policy is to add assumptions that we have good reason to think the arguer believed and used (consciously or unconsciously), which I call "used assumptions" (1982)." It fits under what Ralph Johnson calls the "conservative" approach (1996, p. 67). In this used-assumption, conservative approach, the goal is to appraise the arguer or the arguer's presentation (the argument that the arguer had in mind), or both. We do this sort of assumption ascription when grading students' papers, when deciding whether to include a submitted paper on a program, when evaluating a job candidate's argument in a public presentation, when deciding to whom to give an award for the best paper, when deciding whether Hume, for example, was a superb philosopher, etc. We are charitable only to the point that we supplement the argument with what we have good reason to believe that the arguer believed and used in formulating the argument. We do not try to improve upon what we believe the arguer had to offer. Doing that would be too much charity, given the goal of appraising the arguer or the presentation.

Let us, for the sake of illustration, assume that the goal in appraising the pathologist's moderate-force argument is evaluating the pathologist and the pathologist's presentation, although in that situation, this was not our goal. Our goal actually was to decide about the truth of the conclusion. We actually wanted to know whether the blow was of moderate force, but I shall set that goal aside for the moment (returning to it later) and assume that we are evaluating the presentation and the presenter.

Operating under this temporarily-assumed goal, we might add propositions that "remain within the orbit of the arguer's beliefs" (to use Johnson's (1996, p. 68) apt phrase), for example, propositions that are commonly believed by pathologists, or propositions that are common knowledge, or propositions that we have heard her state, etc. But this leaves us with an almost infinite number of choices. What goes into this argument?

Applying the used-assumption approach to the moderate-force argument, we, assuming the pathologist to be reasonable, would not add the simplest-appearing, deductive-validity-producing proposition to her argument because we would evaluate the resulting argument, and would, as I have shown, deem the result to be a bad argument. This is because the added proposition is false. So we decide that this is not her argument. The added proposition is probably not within her orbit of belief. She knows better, we decide. 
Note that there is some built-in conflict between this conservative, used-assumption strategy and the three-stage approach. The used-assumption strategy usually assumes the arguer to be reasonable and tries to add assumptions that help construct a reasonable argument, making use of the beliefs and statements of the arguer, as exemplified in the previous paragraph. So some evaluation is needed prior to classification, contrary to the classification-first requirement of the threestage strategy. This problem even existed in the deductive-assumption policy; at the first stage of the three-stage approach, identifying the argument, we had to judge whether the proposed assumption actually made the argument deductively valid, an evaluative procedure.

Ignoring that built-in conflict for the time being, we might consider adding more-complicated propositions that make her argument deductively valid, such as, "Knife blows that penetrate $2 \frac{1}{2}$ inches and do not produce any marks on the bones of the victim are of moderate force, if the victim was not wearing a heavy leather jacket and did not raise his arms. The victim was not wearing a heavy leather jacket and did not raise his arms." But again this complex addition is false because there are still other refuting possibilities, such as the possibility that the victim was wearing a large heavy medal, or had a magazine under his shirt, as the pathologist would no doubt realize. A little reflection tells us that the list of possible exceptions is at least very long and that the pathologist would know this. It seems unlikely that we will be able to construct a sound used-assumption argument for the pathologist. If you are thinking I should add a "ceteris paribus" clause, be patient. I will consider that idea later in the qualified reasoning section.

I shall also postpone to later the rest of this construction of the pathologist's argument because, now that it is roughly clear what I mean by 'ascribing used assumptions', we already have enough information to see that the three-stage approach does not work for used assumptions, given any of the ways I have considered of attempting to distinguish between deductive and inductive arguments. Consider:

The standard psychological approach and Beardsley's approach do not work because they, as before, classify this as a deductive argument (based on the pathologist's stance), and it seems clear that any deductive completion of the premises will include a false premise. Thus a good argument must be judged defective under the standard psychological approach and under Beardsley's approach.

The belief/deductive-validity (Vorobej's) version of the psychological approach works for this example whether or not the pathologist has the concept of deductive validity: Either way, her argument would be judged non-deductive, so we are free to try to construct an argument that within the orbit of her beliefs satisfies some other set of standards. So we should look around for a set of standards under which some argument, constructed within her orbit of beliefs, fares best. To be less charitable, assuming she is reasonable, would not seem fair. (Note that again, contra the three-stage approach, we would be bypassing the requirement of 
classification before evaluation, as seems inevitable if we try to be fair in assumption ascription).

But this belief/deductive-validity approach would not work for arguments like the thunderstorm example, if the arguer does not have the concept of deductive validity, because the application of deductive standards (which are the ones by which the argument succeeds), would be precluded by the arguer's not having the concept of deductive validity. So there are some arguments that the belief/deductive-validity approach can not handle under the used-assumption policy.

The achievement approach would be partly satisfactory for the pathologist's moderate force example (I say "partly" because we must overlook the fact that evaluation of the argument precedes classification in the achievement approach). If the approach were to classify the argument as deductive, then the argument would be also unsound, making the approach unsatisfactory. But under the usedassumption policy, one is free not to add the specified complex deductive assumption-or any deductive assumption, and to construct an argument within her orbit of beliefs that satisfies inductive best-explanation standards (again evaluating before classifying). However, the achievement approach does not classify arguments that are not valid (in broad or narrow sense), so it would not always succeed even to this extent.

The generalization approach also does not work: The pathologist's argument does not have a generalization as the conclusion, so it can not be classified as inductive under this approach. If we try to construct an argument within the pathologist's orbit of beliefs that includes a generalization in the reasons, then the argument would be classified as a deductive argument. In order that it be deductively valid, as we have seen, the generalization would have to be false. So the generalization approach either fails to classify the argument or it forces us to declare a good argument to be defective.

In sum, none of the approaches to distinguishing deductive from inductive arguments can be depended on when one is ascribing used assumptions (the conservative approach), especially in the application of the three-stage process

\section{Trying to decide whether the conclusion is true or acceptable: Ascribing needed assumptions}

The fourth assumption-ascription policy is to add assumptions in so far as they are needed to construct the strongest unbiased argument for the conclusion (even if the assumptions are not part of the arguer's orbit of belief), making use of the arguer's explicit reasons. I call the assumptions so added "needed assumptions" (1982). ${ }^{12}$ They fit what Ralph Johnson calls the "liberal" approach (1996. P. 67). Here the goal is to decide whether the conclusion is true, or acceptable, a goal that in real life is the most common goal of argument appraisal and actually was the jurors' primary goal in appraising the pathologist's moderate-force argument. Under this approach, we simply build the best argument we can, making use, among 
other things, of what the arguer said. Because the arguer's orbit-of-belief constraint no longer operates, we are not prevented from adding assumptions and facts that we know, whether or not we believe them to be within the pathologist's orbit of belief. However, because the pathologist was an expert, the jurors justifiably were especially concerned about her reasons. ${ }^{13}$

We can postpone the rest of this depiction and avoid going into all the refuting details again. It should be apparent from the previous sections that the putative distinction between deductive arguments and inductive arguments is not viable under a needed-assumption-ascription policy in which we are trying to decide about the truth or acceptability of the conclusion. It should also be apparent that the three-stage classification-first strategy still does not work. The pathologist still believes, and would claim, that her evidence gives conclusive support for the conclusion; there would still be arguments that are neither inductively nor deductively valid under the achievement approach; there still are people who do not have the concept of deductive validity; and there still are arguments that do not lead toward or away from a generalization. Furthermore, this policy also requires evaluation from the outset, so again classification prior to evaluation is not feasible.

\section{The mixed assumption-ascription policy: Adjusting the assumption-policy} to suit the goal of argument appraisal in the given situation

The fifth assumption-ascription policy, goal-oriented assumption ascription, is one of deliberate flexibility in the selection of one of the other policies, depending on the goal of argument appraisal in the given situation. I have already outlined the goals that justify the used-assumption and needed-assumption policies. The noadded assumption-policy is justified in circumstances requiring an airtight deductive proof, such as a deductive-logic examination, or a deductive proof of a so-far unproved theorem. The deductive-assumption policy is useful when the goal is to probe or explore an argument, or to make a quick guess at the implicit parts of an argument that might deserve challenge or need defense.

Because the three-stage strategy and the putative distinction between deductive and inductive arguments are not viable in each of the first four assumptionascription policies, they must also be not viable under the fifth flexible, goal-oriented policy, since it leads to some one of the first four, depending on the situation

In sum, the three-stage strategy does not work, and no useful distinction can be drawn between deductive and inductive arguments under the inflexible noadded-assumptions policy, the inflexible simplest-deductive-assumption policy, the used-assumption policy, the needed-assumption policy, and the mixed policy. I have seen no other plausible approaches to assumption ascription. 


\section{Section III. Qualified reasoning}

Not only do most real arguments call for assumption ascription, but the reasons and/or conclusions often have implicit or explicit qualifications, such as 'generally', 'rarely', 'probably', 'prima facie', 'ceteris paribus,' etc. Arguments containing such qualifying words explicitly or implicitly are very common. Consider Example 5, an argument I once offered, which explicitly contains the qualifying words, "rarely" and "probably" (italicized in the example):

\section{Example 5:}

Raccoons rarely attack a human when they do not feel threatened and do not feel that their young are threatened. That raccoon ambling across the yard does not feel threatened by us and its young are not around (and so the raccoon does not feel that its young are threatened). So the raccoon will probably not attack you, even though you are within fifteen feet of it.

This raccoon example is a case of qualified reasoning because of its qualifying words.

Note that the intended conclusion does not necessarily follow from a nonuniversal generalization like the one in Example 5, even if the argument would be deductively valid without the qualifying word, 'probably', and with the word 'rarely' changed to 'never'. We can see that it does not follow necessarily (as is) by realizing that I might well believe the first propositions in the first two sentences, but also believe that the raccoon is rabid. In that case I would be wise not to draw the conclusion from the given reasons. How then could the conclusion follow necessarily from them?

How should such arguments be handled? It might be suggested that these words could all be converted to numerical probabilities, making the raccoon argument deductively valid. But what exact number or exact range of numbers goes with 'probably', 'rarely', 'generally', 'prima facie', or 'ceteris paribus'? We need exactness to do a deduction, even when ascribing confidence limits.

The word 'probably' provides an additional problem. Although 1 shall not argue the point here, I (like Toulmin, 1964, p. 53) see the use of 'probably' as a speech act giving a qualified guarantee or endorsement, making (in my view) the concluding of statements containing this word (when it is not in the premises) alien to deductive logic. Even if this speech-act account is rejected, there is still the problem that no exact probability number or range can reasonably be offered in replacement of the word "probably" in Example 5, which I think to be a good argument in the context in which it appeared. 
Qualified reasoning is generally avoided in critical thinking textbooks, possibly because people do not notice the prevalence of qualified reasoning, or they feel that we do not have good advice to give. There certainly is no widely accepted set of standards for dealing with qualified reasoning. This lack of standards deserves much more attention than it receives in the literature. ${ }^{14}$ Even the question of whether it is a problem deserves more attention. Statistical syllogisms are not the answer, partly because no reasonable ways exist to assign numbers to the terms. Bayesian inference suffers from problems noted by Deborah Mayo (1996), among others.

Qualified reasoning constitutes a problem not only for the three-stage approach, but also for any argument appraisal strategy that attempts to be comprehensive. There is insufficient space in this essay to deal adequately with the topic, even if my ideas were fully developed. The best I can offer here is sketch of a solution in the next section of this essay, and a declaration of intention to deal more thoroughly with the topic at some other time and place. But we do face qualified reasoning arguments all the time in our everyday lives, and have an obligation to give our students the best advice we can muster about them.

\section{Section IV. A proposed solution}

It seems that the three-stage classification-before-evaluation strategy has severe problems. An alternative approach that I believe most of us who teach (or have taught) the three-stage view actually employ ourselves, though perhaps without being aware of so doing, abandons the requirement that we classify before we evaluate-in favor of a strategy of often-repeated, situationally-sensitive, successive application of sets of standards, usually accompanied by and concurrent with goal-oriented assumption ascription. Actually 1 began to exemplify this strategy in considering the used-assumption, evaluate-the-arguer-or-the-presentation policy in Section II. The proposed strategy has five crucial interdependent phases, about some of which I shall have more to say after listing them:

(1) It retains the early identification, ordinarily at the commencement of the argument-appraisal process, of explicit argument parts: the conclusion(s) and the explicit reason(s).

(2) It calls for flexibility in deciding whether assumptions should be added and if so, in deciding how charitable to be, letting these decisions depend on the situation, especially the goals of the argument appraiser.

(3) It eliminates the argument-classification stage.

(4) Instead of calling for identification of the type of argument, it calls for the argument appraiser to apply successively a variety of sets of argument standards, usually in conjunction with assumption ascription, stopping only when the argument satisfies a set of standards (in which case the argument is deemed a good argument), or when the set of sets of standards is exhausted without any set being satisfied (in which case it is deemed a weak or poor argument). ${ }^{\text {s }}$ 
(5) It adopts an experience-and-situation-based adjustment of standards when qualifying words like 'generally' and 'probably' appear explicitly, or implicitly (as when 'ceteris paribus' and 'prima facie' apply) in the reasons or conclusion.

\section{Identification of parts of the argument}

Identification of the conclusion and reasons seems straightforward, though beginners often have difficulty. Making it more difficult is the fact that argument appraisal is sometimes even needed right here at the beginning - when the identification of the actual conclusion or reason is in doubt. For example, we might think, in deciding whether a proposition is the conclusion, "This proposition could not be the conclusion. It receives weak support in the rest of the argument. That other proposition is probably (note the non-numerical qualifier!) the conclusion because it receives strong support." This sort of thinking involves argument appraisal without prior classification in the process of identifying a conclusion.

\section{Flexibility in approaches to argument supplementation}

Different goals of the argument appraiser call for different assumption-ascription policies, including different amounts of charity, as described earlier. Appraiser goals include (1) deciding whether a rigorous deductive proof has been provided (calling for a policy of few or no added assumptions and little or no charity); (2) probing an argument or making a quick guess about crucial implicit parts of the argument (calling for a policy of adding a simple deductive assumption, and little or no charity in the ascription); (3) evaluating the arguer or the arguer's presentation (calling for a policy of charity in argument construction limited by the arguer's orbit of belief); and (4) deciding whether the conclusion is true or acceptable (calling for a policy of full charity in the construction of the strongest unbiased argument the appraiser can construct that incorporates what the arguer said, or in some cases at least the true and relevant parts of what the arguer said). It was this last goal that we jurors were pursuing in dealing with Example 1, the pathologist's moderate-force argument.

A fifth policy is flexibly adjusting one's assumption-ascription policy to fit the goals that obtain in the situation. Let the policy depend on the appraiser's goals, instead of insisting on only one policy for all occasions. This flexible policy is an integral part of the argument-appraisal strategy I am here recommending.

In the first section of this essay, the first policy (no added assumptions) was assumed and exhaustively explored in the three-stage-appraisal-strategy context. In the second section, the simple deductive-assumption policy was carefully considered, and exemplification of the used-assumption and needed-assumption policies was commenced. Further elaboration is needed for these two, which respectively accompany the goal of evaluating the person or the presentation, and the goal of making a decision about the truth or acceptability of the conclusion. 
Appraisal of a person or a person's presentation (Calling for partial charity in the ascription of used assumptions)

In Section II, I elaborated the ascription of used assumptions up through the exploratory addition of ever more complex deductive assumptions in an attempt to show that under this policy, the three-stage strategy and the deductive/inductive argument distinction were not viable. The example was the pathologist's moderate-force argument, and I assumed temporarily-for the sake of the exemplification-that the goal was to evaluate the pathologist and the pathologist's argument as she conceived it. I considered a complicated generalization that took account of two counterexamples to the simplest generalization. The generalization was false. I judged it to be an unacceptable candidate for the pathologist's assumption(s) because the pathologist knew better than to accept it. It was probably not in the orbit of her beliefs, and it seemed that any of an increasingly complex series of possible assumptions that make the argument deductively valid would also be false and not in the orbit of her beliefs. The orbit-of-beliefs constraint seemed to rule out any of these possible versions. But if they had not been ruled out by that, then I would have applied soundness standards and found that the argument did not satisfy them because of at least one false premise.

This does not show that the pathologist's argument is unsatisfactory. It only shows that it does not satisfy soundness standards

A reasonable next step is to see whether the argument might satisfy some other set of standards. In this case, best-explanation standards seem like a possibility, since the conclusion is not a value judgment and is not a generalization.

Does the conclusion explain some evidence? Yes, it explains why the wound was only $2 \frac{1}{2}$ inches deep. A number of alternative explanations of the depth of only $21 / 2$ inches (actually, all the ones that occur to me) are ruled out or probably ruled out by the evidence of which she and the jurors were aware. One of these alternative hypotheses, that the blow was of powerful force but was blocked by the bones, was made unlikely by the fact mentioned in her testimony that there were no marks on the bones. Here I have ascribed to her the proposition (as a used assumption) that powerful knife blows that are blocked by bones make marks on the bones.

Here are some other examples of ruled-out hypotheses: The detective's testimony that the only upper clothing that was found near the victim in addition to his $\mathrm{T}$-shirt was a light jacket found lying near his body probably rules out the possibility that a heavy leather jacket diminished the force of the blow (given the ascribed used assumption that a leather jacket had not been removed by someone). The photo of the victim and the testimony that nothing else was found on or near the victim's body seemed to rule out the interference by a magazine or medal. The clean 45-degree wound reported by the pathologist probably ruled out the hypothesis that the victim threw up his arms to defend himself (given the ascribed used 
assumption that such interference would probably have made a messy wound). The hypothesis that the victim's flesh was considerably tougher than ordinary flesh would have been ruled out by a used assumption I attribute to the pathologist-that the victim's flesh was typical of that of humans-an assumption that seems reasonable.

Is the conclusion inconsistent with any known facts? I know of none. Was the conclusion plausible? It seems not to be wildly implausible, even though there was testimony that the defendant had threatened to kill the victim, and at another time had threatened him with a baseball bat. People vary from one day to the next in the strength of their dispositions to violence.

What I have just tried to do is to construct a rudimentary argument within the orbit of the pathologist's beliefs, following the used-assumption policy of assumption attribution. The argument satisfies best-explanation inductive standards better than deductive standards, and there appear to be no other standards available (given my taxonomy). So I choose this version of the argument, apply best-explanation standards again (because these are the ones that guided the construction of the selected argument), and judge it to be inductively valid, using the following bestexplanation standards for construction and appraisal:

(a) The reasons should be acceptable.

(b) Best-explanation inference standards should be satisfied. The first three of these are necessary conditions; the fourth is desirable.

(1) The conclusion should explain facts.

(2) Plausible alternative hypotheses should be ruled out.

(3) The conclusion should be consistent with known facts, and a reasonable effort should have been made to uncover facts inconsistent with the conclusion.

(4) The conclusion should be plausible.

In steps that might for convenience sometimes be combined but that are analytically distinct, I used best-explanation standards twice, first in constructing a version of the argument that is stronger than any others I can construct, and second in deciding whether the selected argument is inductively valid.

You might disagree with this set of standards for appraisal, and you might disagree with their application in this case. In any case, note that in ascribing assumptions under the conservative policy, evaluation interacts with assumption attribution and makes classification unnecessary. I never did classify that argument. Instead, I successively evaluated several combinations of the explicit argument and sets of possible assumptions, using two different sets of standards; and ascribed assumptions (within the arguer's orbit of beliefs) that produced the strongest resulting argument, still assuming that the arguer is reasonable. I did not see any way to shape it to check to see whether it meets still other types of standards, but if I did, I could then have tried to shape it to see whether it meets any of those sets of standards. 
The argument shaped to meet best-explanation standards is a good argument (by best-explanation standards), and the various ones shaped to meet deductive standards are bad arguments because they contain at least one false premise. So I judge the argument to be a good one, and the arguer to be competent because the argument satisfies a legitimate set of standards.

(Note that the result seems somewhat odd because, as assumed in the usedassumption approach to assumption ascription, the goal is to evaluate the presentation and the arguer-not the conclusion (except as an implication of the evaluation). But in the courtroom context, our primary concern was actually whether the conclusion is true, so the truth-seeking needed-assumption approach to assumption ascription is actually more appropriate for that context. That is the next topic.)

If I feel that I can not assume an arguer to be reasonable, then, using whatever clues I can find, I build the argument that I think the arguer had in mind. Then I successively apply sets of standards until I find a set that the argument satisfies, or run out of sets of standards, in which case I would judge the argument unacceptable, and the arguer deficient in this instance.

\section{Truth seeking (Calling for full charity)}

A decision about whether to accept the conclusion is usually my concern when someone offers me an argument. The moderate-force argument, contrary to the for-the-sake-of-illustration assumption I made in illustrating the used-assumption, partial-charity approach, actually fits under the truth-seeking, full-charity approach, given the courtroom context. Accordingly, in order to appraise it, I construct the best unbiased argument I can, utilizing what is at hand, including what the arguer offered, and assumptions and facts that help as much as possible (needed assumptions), realizing that even the most helpful assumptions might still be dubious or worse-and thus a source of weakness of the argument. I do the best I can for the conclusion, giving it every chance to be supported, but at the same time attend to and search for the weaknesses that are and are not mentioned by the arguer. The process is one of continuous interaction between construction and evaluation, and continues until I have the best argument that I can develop-without ignoring its weaknesses. In this process, I usually give special attention to the reasons and argument structure offered by the arguer-at least out of respect for the person who has gone to the trouble to formulate the argument. But if the arguer is an expert in the field-or a highly respected person in the topic, I justifiably pay even more attention to the arguer's reasons and argument structure. I expect such arguers to have given considerable informed thought to the topic.

However, although many aspects are similar to the used-assumption policy, I am not constrained by the arguer's orbit of belief. We jurors observed when we visited the defendant's home what we would later deem to be sufficient room between the walls, ceiling, cabinets, and other furniture for the defendant with her right hand (She was right-handed.) to deliver and withdraw a 45-degree knife 
stroke in the same direction, leaving a clean wound. Perhaps the pathologist had this knowledge, perhaps not. But we made use of this fact, and it did not matter whether it was in the pathologist's orbit of belief.

Because we learned little about this specific case other than from the testimony and evidence given in the courtroom, the argument that we jurors could build under the needed-assumption approach differs little from the one I just built under the used-assumption approach. We knew little that the pathologist did not know.

Under a needed-assumption policy, as with a used-assumption policy, evaluation (interacting with assumption-attribution and other aspects of argument identification) comes early, and classification by type of argument is unnecessary. Under the flexible, goal-oriented policy, we would use the needed-assumption approach to assumption ascription because the goal was to judge the truth or acceptability of the conclusion.

In sum, under the used and needed assumption-attribution policies, we successively evaluate the candidates for the total argument, and end up selecting the best, given the constraints. An exception to selecting the best occurs when the goal is evaluating the arguer or the presentation and the assumption that the arguer is reasonable is not made. Then we just do the best we can to figure out the full argument, and successively apply sets of standards.

Incidentally, classical arguments by philosophers generally call for a mixture of the truth-seeking and presentation-and-arguer-appraisal goals. For example, in appraising Mill's argument for freedom of speech, or Descartes' attempt to refute universal doubt, people are usually interested in the acceptability of the conclusion, but often also in appraising the arguers and their arguments for their own sake. Furthermore, in pursuing an interest in the acceptability of their conclusions, prudence calls for close attention to the thinking that these able philosophers did about their topics.

\section{Successive application of sets of standards}

The successive-application-of-sets-of-standards approach looks at the deductiveinductive (and other) distinction as one between (or among) sets of standards for judging arguments rather than a distinction between (or among) types of arguments. The failure of the putative distinction between (or among) types of arguments is a significant cause of the downfall of the three-stage, classify-beforeevaluate strategy that was the topic of the first two sections of this essay. The strategy that I am suggesting here does not need that distinction. It does, however, employ a distinction among types of argument standards.

There are different sets of standards, including, in my view, soundness standards, inductive standards (including best-explanation standards and standards for generalizing from instances), and value judging standards, all of which are subject to qualified-reasoning adjustments. Using the sets-of-standards approach, we are not required to classify an argument before evaluating it. Instead we successively 
apply sets of standards. We then accept the conclusion if, in the context, it satisfies any set of standards-remembering the set of standards that it satisfies, and showing this, if need be, in appropriate qualifications to the acceptance of the argument or the conclusion. If the argument satisfies no set of standards, the argument is deemed defective.

As I have illustrated, this successive application of sets of standards is interdependent with the second feature, the supplementation of the original explicit argument in accord with the goal(s) in the situation. This interdependence is evident in the continuous appraising and refining of those arguments that are allowed by the goals to be expanded beyond their original explicit reason(s) and conclusion(s). This appraising and refining occurs both when the goal is appraising the person (or the person's work), and when the goal is finding the truth, although more charitable supplementation is allowed for the latter than for the former. However, for those arguments to which no supplementation is permitted by the situation, there is simply appraisal-ordinarily, in this sort of situation, only by deductive or soundness standards because such arguments generally occur in situations requiring logically rigorous proof.

In what follows, I shall briefly explain my approach to argument appraisal standards and a taxonomy thereof, but for the most part shall not defend it. My goal instead is to provide an example of a possible structure to which my recommended argument-appraisal strategy can be applied.

But first, I want to elaborate my stance in this essay toward the particulars of argument standards: The theses of this essay do not include the details of the appraiser's sets of standards and of the appraiser's taxonomy of standards, except for the suggestions for dealing with qualified reasoning - and the other theses can stand without the adoption of my qualified-reasoning suggestions The standards and taxonomy I favor are used for illustration purposes only. However, I do use best-explanation standards to appraise the pathologist's moderate-force argument. I use them to support my contention that it is a good argument. But please feel free to incorporate your own sets of standards, if they differ, into this successive-application-of-standards approach, and, as well, to evaluate the pathologist's moderate-force argument.

\section{Constraints on choosing applicable sets of standards}

One factor that eliminates the application of some sets of standards is the nature of the conclusion. Given the taxonomy that 1 favor, if the conclusion is not a generalization, then inductive generalization standards do not apply, though inductive best-explanation standards might be satisfied. Furthermore, if the conclusion is a value judgment, best-explanation standards do not apply to the argument leading directly to that conclusion because value judgments do not causally account for the data offered in their support-though someone's accepting or believing a value judgment could causally account for data. However, best-explanation standards 
might apply to sub-arguments supporting empirical hypotheses and conclusions that in turn support the value conclusion. This point about value conclusions is controversial. One does not need to accept it in order to accept the main theses of this essay. But if one does accept it, then one should bypass the application of best-explanation standards to arguments that lead directly to value conclusions without intermediate conclusions.

\section{Soundness}

Although there could be various ways of ordering the application of sets of standards, I generally find it easier to start with soundness standards, unless it is immediately apparent that the argument would fail them, but might pass some other set of standards. The argument is of course supplemented and adjusted to the extent permitted by the purpose of the argument appraiser in the situation.

Soundness standards require deductive validity and true or acceptable reasons. There are varying interpretations of the deductive validity part of these standards. Two examples are: "It is impossible for the reasons to be true and the conclusion to be false", and "The falsity of the conclusion is inconsistent with the truth of the reasons." Although these variations do make a difference, often an important difference, I am here bypassing these issues. Nor do I discuss here the variety of rules and systems that have been developed to check for deductive validity. Choices among these alternatives do not affect the main theses of this essay.

If the argument satisfies soundness standards, the job is done. We accept the argument and the conclusion, remembering of course that this acceptance is based on the assumption that the reasons are true or acceptable.

The moderate-force argument of Example 1 fails to satisfy these standards. Unsupplemented, it does not satisfy the standards because the conclusion does not follow necessarily from the reasons explicitly given..$^{16}$ Supplementing it with the most obvious deductive assumption, we must, as shown earlier, judge that the argument does not satisfy soundness standards because the ascribed assumption is false.

This constructive process must often be repeated because, even though the first constructed argument might include a false added premise, there are almost always other possible premises that will also make the argument deductively valid. This fact was exhibited in the discussion in Section II of the used-assumption policy.

Try as I may, I have not been able to construct a version of the moderate-force argument that satisfies soundness standards, except some version that, if generalized, turns all valid induction into deduction. But even then, I would first need to apply inductive standards. So we need to proceed to another set of standards.

Note that in the exploratory ascription of deductive assumptions, as in the thunderstorm case and the moderate-force case, the criteria of deductive validity 
are often not really used to appraise the argument. Rather they are used to construct a probe for it. The appraisal task is simply the evaluation of the explicit reasons and the succession of deductive assumptions. This, I believe, is the most common use of the criteria of deductive validity in practical life, contrary to the impression we get in textbooks and courses that teach deductive logic. But this use also makes deductive logic much more applicable in a practical way than many of its detractors claim.

\section{Inductive standards}

In my conceptual scheme, there are two types of inductive standards, ${ }^{17}$ bestexplanation standards and generalization standards. Sometimes both are applicable.

Best-Explanation Standards. Best explanation reasoning standards are used to help us decide whether the conclusion best explains the facts. I listed and exemplified the application of best-explanation standards previously. Oversimplifying to some extent, these standards are embedded in the following conditional: If the conclusion explains facts, if the evidential support is true or acceptable, if the conclusion is not inconsistent with any facts (although reasonable efforts have been made to uncover such inconsistent facts), if there are no plausible alternative hypotheses that explain these facts, and if the hypothesis is plausible, then the argument is probably (or certainly, depending on the strength of the support) a good one. ${ }^{18}$

Generalization Standards. In the taxonomy I favor, the other type of inductive standards are used to judge whether instances adequately support a generalization, the basic standard, roughly speaking, being representativeness, buttressed by sufficiency in number of instances. Randomness is generally recommended (though often not practically obtainable or obtained) in order to make representativeness likely.

I shall not in detail consider standards for generalizing. They can be very complicated, depending on the nature of the generalization and the situation. Textbooks on sampling and statistics should be consulted. But it is important to realize that sometimes both best-explanation and generalizing standards apply, as is likely in an argument for the conclusion that sting rays avoid people, which conclusion explains as well as generalizes over a number of specific instances of sting rays avoiding people. ${ }^{19}$

In any case, standards for generalization should probably be applied next (and often also best-explanation standards) if the conclusion is an empirical generalization about the way things are or behave. If the argument satisfies either or both of these sets of standards, then the conclusion should be accepted, together with at least an implicit qualification occasioned by the fallible nature of empirical knowledge. If there is some doubt about the full satisfaction of the standards, this might 
be signaled by the addition of a word like 'probably.'

Thus far I have only considered deductive and inductive standards. But the sets-of-standards strategy is extendable to any other set of argument standards that is legitimate.

\section{Standards for value judging}

Although much has been said and written about whether we can distinguish value judgments from empirical statements, I here assume that there is a difference. If so, factors that appear to come into play in evaluating arguments supporting value judgments include the consequences of accepting the value judgment, the principle(s), if any, from which the value judgment can be derived, decisions about prior similar cases, and the nature of the situation(s) to which it applies.

One first thing to do is to decide whether the conclusion is a value judgment. If so, then do not apply best-explanation standards. Deductive criteria might come into play through the application of value generalizations or principles to particular cases, as in the application of the principle, "Honesty is the best policy," to the particular case in which we receive an overage in change when purchasing a movie ticket.

However, we have many value principles and they often conflict, so deduction from an acceptable principle often does not settle the matter. This fact requires us to consider (all, or almost all) value principles to be prima facie ${ }^{20}$ (on-the-face-ofit) principles, which, to put it frankly, hold except when there is good reason for them not to hold. It also requires a look at consequences, the details of the situation, and the meaning of the key concepts (like honesty) in order to decide when the principle does and when it does not hold. All of this suggests that value reasoning calls for qualified reasoning adjustments. But I do not want to assume a more precise (and more controversial) position here about the justification of value judgments, even though I have mentioned factors I believe relevant. The point I want to make is that judging arguments leading to value judgments fits into the sets-ofstandards approach, assuming (as I do) that there is a set of value-judging standards: If the conclusion is a value conclusion, apply the standards for value arguments. If the argument is a good one, accept the conclusion, or give credit to the arguer, etc., depending on the purpose of the appraisal.

\section{Qualified reasoning adjustments to soundness standards}

Let us return to the argument about raccoons (Example 5), which contains the qualifying words, "rarely" and "probably", and which I thought to be a good argument in the context in which it appeared, even though it was not sound as explicitly stated:

"Raccoons rarely attack a human when they do not feel threatened and do not feel that their young are threatened. That raccoon ambling across the yard does 
not feel threatened by us and its young are not around (and so the raccoon does not feel that its young are threatened). So the raccoon will probably not attack you, even though you are within fifteen feet of it."

If the word 'rarely' were replaced by 'never', and the word 'probably' were omitted from the argument, then the argument would be deductively valid.

With the words subsequently restored, I judge that in the context it was still a good argument. It satisfies the four criteria I propose for qualified-reasoning adjustments to soundness standards:

(1) that the reasons are true or acceptable in their original wording;

(2) that, with the qualifications removed (or adjusted to convert generalizations to universal statements), the argument is sound;

(3) that, with the qualifying terms replaced, the reasons are believed by the appraiser to justify the conclusion, all things considered-requiring that the appraiser knows of no defeaters to the argument, even though the appraiser has made a reasonably thorough search for defeaters (A defeater, following Pollock (1995, pp. 40-41), is a factor that either shows that the conclusion is not acceptable or that in the situation, the reasons do not support the conclusion.); and

(4) that the appraiser has been conscientious (enough for the situation) in the exercise of experienced, reasonably intelligent, informed judgment.

This fourth criterion, that of conscientiousness in exercising experienced, reasonably intelligent, informed judgment is radically different from the others. It is to be applied to the argument appraiser's qualities and background rather than the content and context of the argument. Its satisfaction (together with the satisfaction of the other three criteria) certainly does not guarantee that the result is justified. It would be easier if things were otherwise, but so far as I can see at this time, this is the best we can do in such circumstances. Using my experienced, informed judgment, and given what I know about where I live and the rest of the world, I think that my raccoon example is a good argument; and it exemplifies a very common form of argument.

Actually this need for experienced, reasonably intelligent, informed judgment also holds for all other arguments, even the most rigorous deductive proof-in deciding, for example, whether the words mean the same from one step to the next. But the need for intelligent experienced informed judgment deserves special emphasis for qualified reasoning.

The qualified reasoning approach can be instructively applied to the simple deductive supplementation of the moderate force example. Recall the simple proposition producing a deductively valid argument, "Knife blows that penetrate $21 / 2$ inches and do not produce any marks on the bones of the victim are of moderate force", which is false. If we assume that there is an implicit ceteris paribus clause, then the proposition becomes more palatable because it allows for exceptions. 
Given that we are willing to ascribe assumptions, would it be better then to use soundness standards exclusively, ${ }^{21}$ sometimes strictly, but often in accord with the qualified reasoning adjustments to soundness? I suspect not, because other sets of standards, like best-explanation standards, give more explicit guidance than those provided by the non-deductive part of the qualified-reasoning adjustments to soundness, which might seem excessively vague and subjective to some. Furthermore, if the taxonomy is to consist only of soundness standards, then subsets of soundness standards would be required (for example, subsets for best explanation, generalization, non-inductive soundness, etc.) and the proposed strategy would be called the successive application of subsets of soundness standards. But I do not want to argue the point in this essay, because it is part of the issue of the proper taxonomy of argument standards. The theses of this essay can be defended without becoming embroiled in that issue, important though it is. If the theses of this essay are accepted, I believe that we will be in a better position to discuss the taxonomy issue.

I realize that my positing those four criteria for qualified reasoning adjustments to soundness constitutes an exception (along with best-explanation reasoning) to my avoiding the taxonomy issue. Partly because of that and the fact that $I$ am still working on the topic I put the four criteria forward tentatively, and invite others to improve upon them

But, in any case, we can not hide from qualified-reasoning arguments. We might not explicitly say, "Honesty is prima facie the best policy." But that is the way we act (concluding, for example, "You should probably be honest here" after saying, "Honesty is the best policy"). We might not explicitly say, "Whenever thunderstorms are nearby, we will have heard thunder in the recent past, ceteris paribus." But we act as if 'ceteris paribus' were there. The inevitability of exceptions to most of our generalizations is so well known and accepted that we do not bother to point out this fact each time we utter a generalization. We generally note this fact only when we want to warn people of a significant possibility that an exception will occur.

Given this widespread utilization of explicit or implicit qualified statements in arguments, qualified reasoning must be faced by teachers of critical thinking. Unless something better comes along, I recommend the approach already sketched. We have to be well informed and make the best judgment we can, given the situation and the strength of the evidence-following Aristotle's advice to let the degree of precision fit the subject matter. ${ }^{22}$

Qualified-reasoning criteria might well be applied immediately after an argument's failure to satisfy strict soundness standards, if it appears on first glance that the argument might be successful under these criteria. The ordering of the application of qualified reasoning criteria and other sets of standards depends often upon hunches and educated guesses.

In my examples, I applied qualified-reasoning criteria only to arguments that 
would be deductively valid with the elimination or adjustment of one or more implicit or explicit qualifications. However, qualifiers often appear in arguments to which inductive (best explanation or generalization) standards-or value judging or other legitimate standards-are being applied. In any case, qualified reasoning procedures must fit the situation, including the set of standards being applied. ${ }^{23}$

\section{Section V. Complex arguments}

Often arguments join together to support an overall final conclusion. The reasons in the final argument might be conclusions of the subarguments. Accordingly I call them "intermediate conclusions". The different subarguments that support these intermediate conclusions of the overall argument for the final conclusion, as well as that final argument itself, might succeed under different sets of standards. But if each subargument and the final argument satisfy some set of standards, then the conclusion to the final argument is probably to be accepted. In deciding whether to accept the conclusion of the final argument, the weaknesses of each of the intermediate arguments should be recognized through the qualifications attached to the intermediate conclusions, so that it is possible that a string of weak intermediate conclusions are not jointly strong enough to make a strong overall argument. It is also possible that one or more subarguments will fail, but that the overall argument will be strong enough without them. Intelligent, experienced, informed, and situationally-aware judgment is required.

The original example, the moderate-force argument, actually is a complex argument. There is a subargument within it leading to the intermediate conclusion that the knife probably did not touch any bones. Its explicit reason was that there were no marks on the bones. This subargument satisfies best-explanation standards. The conclusion that the knife probably did not touch any bones probably explains why there were no marks on the bones. After much thought and with considerable knowledge of the situation, I can think of no alternative explanation of the absence of marks on the bones in that situation; and the conclusion is plausible and consistent with other facts I know about the case. However, because of my ignorance of physiology, I can not leave the conclusion unqualified. Hence "probably".

Incidentally, I also went about checking the proposition that the knife did not touch any bones a different way by adding an assumption to construct a deductively-valid subargument, and decided that the resulting argument did not satisfy the strict standards of deduction. This is because, in spite of my ignorance about physiology, I find implausible the assumption I added, which is that whenever there are no marks on bones, the intruding knife did not touch any bones. However, I qualified the assumption and conclusion (by adding 'generally' and 'probably', applied the qualified reasoning approach, and judged the argument acceptable, using soundness standards adjusted by qualified reasoning criteria ("qualified soundness standards", for short). Recall that it is also acceptable using best-expla- 
nation standards. There is nothing wrong with an argument's satisfying two sets of standards.

This intermediate conclusion ('The knife probably did not touch any bones') was a reason used in the final argument in two ways. One was in helping the final conclusion to explain why the knife went in $2 \frac{1}{2}$ inches (rather than less). The intermediate conclusion also helped the final argument by (in another subargument) supporting the ruling out of an alternative hypothesis, 'The blow was of strong force.' If the alternative hypothesis were true and the knife probably did not touch any bones, then the depth of the wound would probably have been greater than $2 \frac{1}{2}$ inches, assuming that there were no other obstructions. But the wound was no greater than $2 \frac{1}{2}$ inches, and I am willing to assume that there were probably no other obstructions, so the alternative hypothesis is probably ${ }^{24}$ false (another intermediate conclusion). I believe that this sub-argument satisfies qualified soundness standards (qualified denial-of-the-consequent, or qualified modus tollens, so to speak).

So, according to my application of sets of standards, the overall moderateforce argument is a good one because it satisfies best-explanation standards. There are two intermediate conclusions, the first of which satisfies best-explanation and qualified soundness standards, but not strict soundness standards, and the second of which satisfies only qualified soundness standards, but not strict soundness standards.

In appraising the total argument, I did not need to decide in advance what type of argument it was, though I did subconsciously decide that it was not an argument leading directly to a value judgment or a generalization because the conclusion is not a value judgment or a generalization. I successively applied varied sets of standards, and found that each part of the argument satisfied some set of standards. I constructed arguments by adding plausible needed assumptions because my primary interest was in deciding whether to accept the conclusions, not in evaluating the arguer, and not in checking an allegedly rigorous deductive proof.

\section{Section VI. Summary and comment}

What I have called the "three-stage strategy" of argument appraisal consists of three sequential stages: (1) identify the parts of the argument; (2) classify the argument type (deductive, inductive, etc.); and (3) evaluate the argument by applying the set of standards appropriate for the type identified. This strategy has unacceptable interdependent difficulties:

First, the putative distinction between deductive and inductive arguments does not work in a classify-before-evaluate context, regardless of the policy toward assumption ascription, and regardless of the version of the attempt to distinguish between inductive and deductive arguments. Three main accounts were considered, the psychological, achievement, and generalization accounts, as well as 
Beardsley's hybrid disjunctive account and Vorobej's ingenious belief version of the psychological account. On the other hand, a distinction between deductive and inductive argument standards (not arguments) is tenable and useful.

Second, assumption-ascription policy is generally unclear and not comprehensive (though this problem is extends beyond the three-stage approach).

Third, the approach does not deal with qualified reasoning, which is a manner of reasoning that is very common and contains explicit or implicit qualifiers such as 'probably', 'generally', 'ceteris paribus', etc.

I propose an alternate approach to argument appraisal, calling for

(1) the identification of the parts of the argument;

(2) flexibility in the amount of charity associated with assumption ascription, depending on the appraiser's purpose;

(3) the abandonment of attempts to classify arguments into types such as inductive and deductive;

(4) the successive application of sets of standards in assumption ascription and in the appraisal of the argument that is before us; and

(5) a realistic, experience-based loosening of, especially soundness, standards in qualified reasoning, requiring intelligent, experienced, informed judgment, tempered by flexibility toward the degree of precision needed in the situation.

There is more to be said about all of these topics, and further refinements are needed. On some important questions, I have not argued for a position (though on occasion have assumed one), such as, "Should we focus on truth or acceptability of the reasons?" and "What are the components of a valid taxonomy of argument standards?" Furthermore, my treatment of qualified reasoning is admittedly tentative and incomplete. So, this essay is not as comprehensive as I would like. However, it is comprehensive enough to make its basic points.

Finally, as part of this summary, I have added an appendix containing rough guidelines for student use in following the sets-of-standards approach. In including it, I accomplish two purposes. One is to organize and present the approach in enough detail to make it usable in practice. The other is to satisfy my deep feeling that that the quality of, and often even the meaning of, philosophical activity depend on its practical implications and applications. 1 hope you will read it, adjust the taxonomy if you so desire, use it, and let me know how it works out.

\section{Appendix: Guidelines for pursuing the five-phase sets-of-standards}

These guidelines for argument appraisal constitute a summary of the process. They are complex, but there are still unstated qualifications and nuances that will become apparent with experience. The main ideas presented here should give you a good start. The steps are presented in order, and require knowledge of the topic and careful attention to the context:

I. Identify the conclusion and explicit reasons. If it is a complex argument, identify the intermediate conclusion(s) and the final conclusion, and prepare 
to consider each part and the total.

II. Determine the nature of each conclusion and intermediate conclusion (empirical or value, general or specific, etc.). If it is a value conclusion, do not apply best-explanation standards. If the conclusion is not a generalization, do not apply generalization standards.

III. Determine the goal of the appraisal: Are you trying 1) to decide whether the conclusion is true or acceptable, 2) to appraise the arguer, or the arguer's presentation (the argument as presented by that arguer), or 3 ) to decide whether a deductive proof is deductively valid?

IV. Prepare an argument for final appraisal.

A. If the goal is to decide whether the conclusion is true or acceptable, construct the best unbiased argument you can, making use of the reasons provided by the arguer. Construct a series of candidates for the final argument by ascribing a series of possible sets of needed assumptions, and successively applying sets of standards to each constructed argument candidate. Employ any knowledge that you have or can reasonably acquire. Search out and take account of weaknesses, and make use of your intelligent, experienced, situationally-aware judgment, to the extent that you are able. Select the best candidate as the final argument.

B. If the goal is to appraise the arguer or the arguer's presentation, construct as well as you can the full argument that the arguer had in mind-consciously or subconsciously. Add assumptions that the arguer apparently used consciouslyor subconsciously but did not mention-assumptions that you think the arguer would think would help the argument. In doing so, you should, as in the previous paragraph, construct a series of candidates for the final argument, but this time pick the one within the arguer's likely orbit of beliefs that is most likely to be approved by the arguer, given your successive application of sets of standards. Assume that the arguer is rational, unless you have reason to think otherwise, in which case use whatever clues are available in building an argument within the arguer's orbit of beliefs.

C. If your goal is the appraisal of a supposedly rigorous deductive proof of a theorem, ordinarily be prepared to add little or nothing to the argument. The original explicit argument is the final argument.

$V$. Make a decision about the final argument by applying the set of standards used to construct that final argument under $\mathrm{A}$ or $\mathrm{B}$ in IV, or applying rigorous deductive standards for the result under $C$. If you did not add anything under $A$ and $B$ in IV, successively apply sets of standards until the argument satisfies a legitimate set of standards, or you exhaust your set of sets of standards. If the argument satisfies a legitimate set of standards, accept the conclusion and argument. If it satisfies none, reject the argument. Here is a broad outline of four-sometimes overlapping - sets of standards (soundness, two types of inductive, and value judging) plus qualified reasoning criteria: 
A. Soundness standards:

1. The reasons should be true or acceptable.

2. The conclusion should follow necessarily from the reasons.

B. Inductive standards. Apply one set, or both concurrently, if applicable;

1. Best-explanation reasoning standards, applied to conclusions that appear to be capable of explaining (causally accounting for) some facts:

(a) The reasons should be true or acceptable.

(b) Best-explanation inference standards should be satisfied. The first three are necessary conditions, the fourth is desirable:

(i) The conclusion should explain facts.

(ii) Plausible alternative hypotheses should be ruled out.

(iii) The conclusion should be consistent with known facts, and a reason able effort should have been made to uncover facts inconsistent with the conclusion.

(iv) The conclusion should be plausible.

(c) You should be experienced and knowledgeable about the topic, and sensitive to alternatives.

2. Generalization standards (applied to generalizations (proportional, universal, loosely proportional)):

(a) The instances should be acceptable. They must be instances, and they should have actually occurred.

(b) There should be a good case for thinking the instances to be representative.

(c) The instances should be sufficiently abundant, given the sort of thing they are.

(d) The generalization, if proportional, should be consistent with facts to the extent required by the nature of the generalization and the situation.

(e) You should be experienced and knowledgeable about the topic, techniques for assessing representativeness, and sensitive to alternatives.

C. Value judging standards, applicable if the conclusion is a value judgment:

1. The supporting information, if relevant, should be true or acceptable.

2. Supporting principles:

(a) Should be acceptable.

(b) Should imply the conclusion in accord with qualified reasoning criteria

3. The prospective consequences of accepting the conclusion should be acceptable on balance.

4. Relevant situational features should be brought to bear, including prior decisions in similar cases.

5. You should be experienced and knowledgeable about the topic, and sensitive to alternatives. 
D. Qualified-reasoning criteria:

1. The reasons should be acceptable.

2. The argument should be deductively valid without the qualifiers, or strong inductively, without the qualifiers in the evidence; or it should be a strong value argument without the qualifiers in the reasons.

3. With the qualifiers replaced, the argument should still be reasonable.

4. You should be experienced and knowledgeable about the topic, and sensitive to alternatives.

\section{Notes}

'For helpful advice, I am indebted to Richard Anderson, Sean Ennis, Alec Fisher, Daniel Flage, Nancy Hancock, Paul Newberry, Shirley Pendlebury, Arnold Wilson, and Nancy Wilson. I am especially grateful to David Hitchcock and Perry Weddle for their several insightful commentaries. Earlier versions of this paper were presented at The Eighth Greater Boston Institute on Teaching Thinking, July, 1998; a meeting of the American Association of Philosophy Teachers, Mansfield, PA, August, 1998; a meeting of the World Congress of Philosophy, Boston, August, 1998; and a colloquium at The University of Wisconsin, Parkside, September, 1998. I appreciate the comments and suggestions made by the participants in these sessions.

${ }^{2}$ A similar suggestion was made by David Hitchcock $(1980,1981)$ and Brian Skyrms (1975, p. 12).

${ }^{3}$ A view expressed by Govier (1999, p. 110), though there are differences in elaboration. 'In my text, I use 'is supposed to', as in "the conclusion is supposed to follow necessarily...." (1996, p. 396), with a meaning approximating "is intended to", or "is meant to", so the forthcoming criticisms apply to the version appearing in my text, although I did not there endorse the three-stage strategy.

${ }^{5}$ Weddle has observed, "Some traditionally inductive....arguments provide conclusive grounds for their conclusion...." $(1979$, p. 4). Govier noted that "shows conclusively" will not provide a reliable basis for inferring that [the arguer thinks that] the premises are supposed to logically entail the conclusion" $(1980$, p.7).

"Studies such as those reported by Scribner (1979) about people in non-literate cultures, though seeming to conflict with Vorobej's view, probably do not do so. See Ennis (1998) for elaboration.

${ }^{7}$ A few books, including those by Johnson \& Blair (1983) and Scriven (1976), do not have deductive parts.

${ }^{8}$ By 'inductively valid argument', I mean, accepting the guidance provided by my dictionaries, one that well satisfies a set of reasonable inductive standards. I am not being inconsistent in objecting to the concepts deductive argument and inductive argument while at the same time speaking, for example, of "deductively invalid argu- 
ments" and "inductively valid arguments". These last two phrases are used to refer respectively to arguments that fail to satisfy deductive standards, and that satisfy inductive standards.

${ }^{9}$ Skyrms (1975) and Weddle (1979) exhibited these difficulties with the generalization approach.

${ }^{10}$ As Nelleke Bak pointed out at the World Congress of Philosophy meeting, 1998.

"David Hitchcock (1985) called them "assumptions of the arguer".

${ }^{12}$ David Hitchcock (1985) called them "assumptions of the argument".

${ }^{13}$ Furthermore, because of her unchallenged expertise, we were also under some obligation to accept her conclusion simply because she as an expert uttered it on the witness stand. But we were not required to do so. It was up to us to determine the facts.

${ }_{14}^{14}$ It has received some attention, as exemplified by work by Nicholas Rescher (1976) and John Pollock (1995), but this attention involves numerical probabilities. Derek Allen (1988), Trudy Govier (1999), Michael Scriven (in an informal e-mail communication in 2000), Alvin Plantinga (1993), Stephen Toulmin (1964) and Perry Weddle (1979) also give attention to qualifiers, so the topic is not totally neglected.

${ }^{15}$ David Hitchcock has suggested something similar: "We should assess it by those standards which give it the best chance of being a cogent argument" $(1981$, p. 15). But he did not offer a stopping rule.

${ }^{16}$ Actually, I did not prove that the argument was deductively invalid, a realization I owe to Gerald Massey (1975).

${ }^{17}$ There does not appear to be a generally accepted definition of 'induction', according to Max Black in The Encyclopedia of Philosophy (1967, p. 170 of Vol. 4). However, he defined 'induction' as "all cases of nondemonstrative argument, in which the truth of the premises, while not entailing the truth of the conclusion, purports to be a good reason for belief in it" (p. 169 of Vol. 4). This is a very broad definition.

${ }^{18}$ As noted earlier, this last criterion is not a necessary condition, though its satisfaction is desirable. The whole set of criteria and examples of their application can be found in my Critical Thinking (1996), pp. 178-263.

"See my "Enumerative Induction and Best Explanation" (1969) for an argument to the effect that not all generalizing can be judged by best-explanation standards.

${ }^{20}$ Extending the prima facie concept beyond duties to other expressions of value.

${ }^{21}$ Advocates include Perry Weddle (1978), Thomas Schwartz (1980), and David Hitchcock (1986), who convert non-deductively-valid arguments to deductively-valid arguments "suitably filled out" (Weddle, 1978, p. 3).

${ }^{22}$ Nichomachean Ethics, 1, 3.

${ }^{23}$ In particular, for the application of qualified reasoning criteria in adjustment of nonsoundness standards, the word 'probably' in a conclusion should be left in place in both evaluations. At the first evaluation, qualifiers should only be removed from the reasons or evidence. This suggestion is an example of the elaboration of qualified reasoning on which 1 am working.

${ }^{24}$ As a step in the direction of support for my contention that 'probably' is not replaceable by a probability number, $I$ invite an attempt to try to so replace the five occurrences of 'probably' in this paragraph by probability numbers. 


\section{References}

Allen, Derek (1988). Inferential soundness. Informal Logic, 10, 57-65.

The American heritage dictionary of the English language (Fourth Edition), (2000). Boston: Houghton Mifflin.

Beardsley, Monroe (1975). Thinking straight. Englewood Cliffs, NJ: Prentice-Hall.

Black, Max (1967). Induction. In Paul S. Edwards (Ed.), The encyclopedia of philosophy (Vol. 4), (pp. 169-181). New York: The Macmillan Company \& The Free Press.

Cederblom, Jerry \& Paulsen, David W. (1986). Critical reasoning. Belmont, CA: Wadsworth.

Copi, Irving (1962). Introduction to logic. New York: Macmillan.

Copi, Irving \& Cohen, Carl (1998). Introduction to logic. Upper Saddle River, NJ: PrenticeHall.

Creighton, James E. (1922). An introductory logic. New York and London: Macmillan. Ennis, Robert H. (1969). Enumerative induction and best explanation. The Journal of Philosophy, 65, 523-530.

Ennis, Robert H. (1982). Identifying implicit assumptions. Synthese, 51, 61-86.

Ennis, Robert H. (1996). Critical thinking. Upper Saddle River, NJ: Prentice-Hall.

Ennis, Robert H. (1998). Is critical thinking culturally biased? Teaching Philosophy, 21 (1), 15-33.

Fohr, Samuel D. (1980). Deductive-inductive: Reply to criticisms. Informal Logic Newsletter, iii (I), 5-10.

Grice, H. P. (1990). Logic and conversation. In A. P. Martinich (Ed.), The philosophy of language (pp. 149-160). Oxford: Oxford University Press.

Govier, Trudy (1980). More on inductive and deductive arguments. Informal Logic Newsletter, ii (3), 7-8.

Govier, Trudy (1987). Problems in argument and evaluation. Dordrecht-Holland: Foris Publications.

Govier, Trudy (1999). The philosophy of argument. Newport News, VA: Vale Press. Harman, Gilbert (1973). Thought. Princeton, NJ: Princeton University Press.

Hitchcock, David (1980). Deductive and inductive: Types of validity, not types of arguments. Informal Logic Newsletter, ii (3), 9-10.

Hitchcock, David (1981). Deduction, induction, and conduction. Informal Logic Newsletter, iii (2), 7-15.

Hitchcock, David (1985). Enthymematic arguments. Informal Logic, vii, (2 and 3), 83-97. Hitchcock, David (1996). Review of Ralph H. Johnson's The rise of informal logic: essays on argumentation, critical thinking, reasoning and politics. Informal Logic, $18(2 \& 3), 269-283$.

Johnison, Ralph H. (1996). The rise of informal logic. Newport News, VA: Vale Press. Johnson, Ralph H. \& Blair, J. Anthony (1983). Logical self-defense (2nd ed.) Toronto: McGraw-Hill Ryerson.

Kahane, Howard (1980). Logic and contemporary rhetoric (3rd ed.). Belmont, CA: Wadsworth. 
Massey, Gerald (1975). Are there any good arguments that bad arguments are bad? Philosophy in Context (Cleveland State University), 4, 61-77.

Mayo, Deborah G. (1996). Error and the growth of experimental knowledge. Chicago: The University of Chicago Press.

Mill, John Stuart (1872). A system of logic (8th ed.). London: Longman Group Limited. Moore, Brooke \& Parker, Richard (1995). Critical thinking. Mountain View, CA: Mayfield. Plantinga, Alvin (1993). Warrant and proper function. New York: Oxford University Press.

Pollock, John (1995). Cognitive carpentry: A blueprint for how to build a person. Cambridge, MA: The MIT Press.

Rescher, Nicholas (1964). Introduction to logic. New York: St. Martin's Press.

Rescher. Nicholas (1976). Plausible reasoning. Amsterdam: Van Gorcum.

Salmon, Wesley C. (1963). Logic. Englewood Cliffs, NJ: Prentice-Hall.

Scribner, Sylvia (1979). Modes of thinking and ways of speaking: Culture and logic reconsidered. In Roy O. Freedle (ed.), New directions in discourse processing II. pp. 223-243. New York: Ablex.

Schwartz, Thomas (1980). The art of logical reasoning. New York: Random House.

Scriven, Michael (1976). Reasoning. New York: McGraw Hill.

Skyrms, Brian (1975). Choice and chance: An introduction to inductive logic (2nd ed.). Encino, CA: Dickenson.

Thomas, Stephen N. (1986). Practical reasoning in natural language. Englewood Cliffs, NJ: Prentice-Hall.

Toulmin, Stephen (1964). The uses of argument. Cambridge: Cambridge University Press. Urdang, Laurence \& Flexner, Stuart Berg (1968). The Random House dictionary of the English language (College Edition). New York: Random House.

Vorobej, Mark (1992). Defining deduction. Informal logic, XIV(2 \& 3), 105-118.

Walton, Douglas N. (1989). Informal logic. Cambridge, UK: Cambridge University Press. Webster's collegiate dictionary (Fith Edition), (1947). Springfield, MA: G. \& C. Merriam Co.

Weddle, Perry (1978). Argument: A guide to critical thinking. New York: McGraw Hill. Weddle, Perry (1979). Inductive, deductive. Informal Logic Newsletter, ii (I), 1-5.

Weddle, Perry (1980). Good grief: More on induction/deduction. Informal Logic Newsletter, iii (I), 10-13.

Weddle, Perry (1987). Informal logic and the deductive-inductive distinction. In Franz H. van Eemeren, Rob Grootendorst, J. Anthony Blair \& Charles A. Willard (Eds.), Argumentation: Across the Lines of Discipline (Proceedings of the conference on argumentation 1986), pp.383-388. Dordrecht-Holland: Foris.

Whewell, William (1858). History of the inductive sciences (Vol. 1). New York: Appleton. Woods, John \& Walton, Douglas (1979). What type of argument is an ad verecundiam? Informal Logic Newsletter, ii (l), 5-6. 